\title{
INITIAL UNITED STATES CLINICAL TRIAL OF ROBOTICALLY ASSISTED ENDOSCOPIC CORONARY ARTERY BYPASS GRAFTING
}

Ralph J. Damiano, Jr, MD

Walter J. Ehrman, MD

Christopher T. Ducko, MD ${ }^{\mathrm{a}}$

Harold A. Tabaie, DO, $\mathrm{PhD}^{\mathrm{b}}$

Edward R. Stephenson, Jr, MD

Charles P. Kingsley, $\mathrm{MD}^{\mathrm{c}}$

Charles E. Chambers, MD $^{\mathrm{d}}$
Objectives: With traditional instruments, endoscopic coronary artery bypass grafting has not been possible. This study was designed to determine the clinical feasibility of using a robotically assisted microsurgical system to create endoscopic coronary anastomoses. Methods and results: Ten patients underwent endoscopic coronary artery bypass grafting of the left internal thoracic artery to the left anterior descending artery. Subxiphoid endoscopic ports ( 2 for instruments, 1 for a camera) were placed, and a robotic system was used to perform the left internal thoracic artery-left anterior descending artery bypass graft. Conventional techniques were used to perform the other grafts. Blood flow through the left internal thoracic artery graft was measured in the operating room and was adequate in 8 of 10 patients. The 2 inadequate grafts were revised successfully by hand. Six weeks after the operation, selective coronary angiography demonstrated a graft patency of $100 \%$ (8/8). There were no technical failures of the robotic system. The only postoperative complication was mediastinal hemorrhage in 1 patient. Conclusions: This pilot study demonstrates the feasibility of robotically assisted endoscopic coronary artery bypass grafting. (J Thorac Cardiovasc Surg 2000;119:77-82)
$T^{1}$ he use of minimally invasive endoscopic techniques has gained widespread acceptance in a variety of surgical disciplines. However, these techniques have had little applicability to cardiac surgery. Although coronary artery bypass grafting (CABG) and valve replacements have been performed through small thoracotomies and limited sternotomies with considerable success, ${ }^{1-5}$ an efficient means of performing totally endoscopic $\mathrm{CABG}$ has not been realized. There are many reasons for this, including the limited accessibility to the coronary arteries and the technical challenges of performing microsurgery with traditional endoscopic instruments. ${ }^{6}$ The length and fixed pivot point of

From the Division of Cardiothoracic Surgery, ${ }^{\text {a }}$ The Milton S. Hershey Medical Center, Hershey, Pa; Cardiothoracic Surgeon, Sarasota

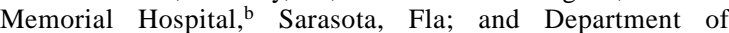
Anesthesia ${ }^{c}$ and Division of Cardiology, ${ }^{d}$ The Milton S. Hershey Medical Center, Hershey, Pa.

Received for publication July 20, 1999; revisions requested Sept 21, 1999; revisions received Oct 5, 1999; accepted for publication Oct 6,1999 .

Address for reprints: Ralph J. Damiano, Jr, MD, Chief, Division of Cardiothoracic Surgery, MC H165, The Milton S. Hershey Medical Center, PO Box 850, 500 University Dr, Hershey, PA 17033 (E-mail: rdamiano@psghs.edu).

Copyright $\odot 2000$ by Mosby, Inc.

$0022-5223 / 2000 \$ 12.00+0 \quad \mathbf{1 2 / 1 / 1 0 3 4 6 4}$ endoscopic instruments have accentuated the effect of the surgeon's tremor, making completion of an anastomosis both difficult and time consuming. ${ }^{7}$ Recent technological developments have addressed the difficulties associated with endoscopic CABG. ${ }^{8,9}$ To overcome the limitations of traditional endoscopic instruments, robotic systems have been developed to enhance surgical dexterity. We have used one of these systems to perform a prospective clinical trial of endoscopic CABG.

The Zeus Robotic Surgical System (Computer Motion, Inc, Goleta, Calif) consists of 3 major components: a surgeon interface device consisting of a video monitor and 2 instrument handles, a computer controller, and 2 robotic arms (Fig 1). The surgeon manipulates the instrument handles, which are identical to traditional microsurgical instruments. The computer controller digitizes the surgeon's motions and relays the information in real time to the 2 robotic arms. These arms are attached to the operating room table and precisely control the instrument tips that are within the surgical field. A third voice-controlled robotic arm is used to hold and move the endoscope.

This system has accurately performed CABG in both cadaveric and in vivo animal studies. ${ }^{10,11}$ This report describes the first prospective, single-center clinical trial to examine the efficacy and safety of robotically 

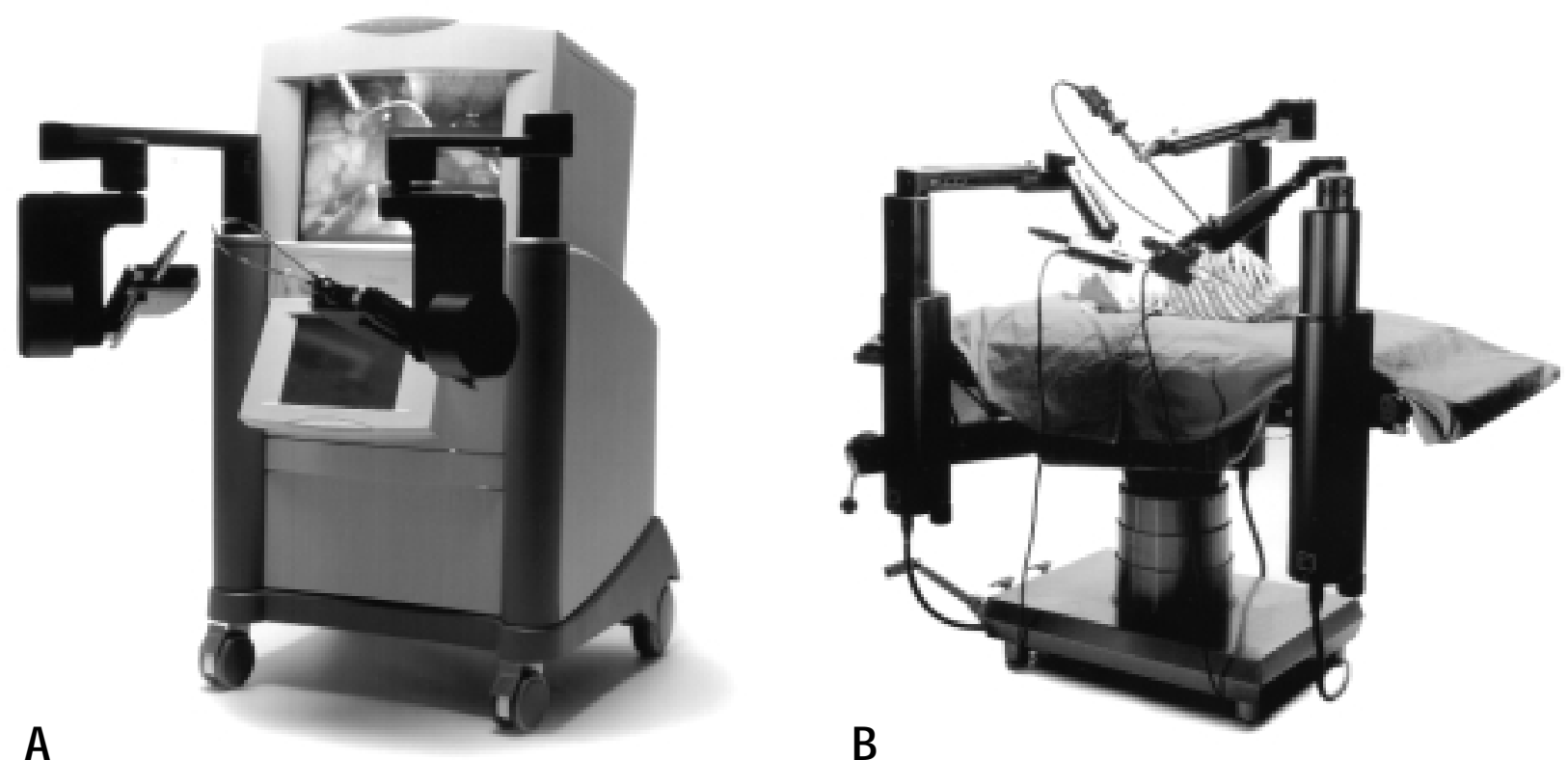

Fig 1. A, The Zeus Robotic Surgical System Surgeon Interface Device. This consists of a video monitor and 2 customized instrument handles. The surgeon manipulates the instrument handles. A computer controller digitizes the surgeon's motions and relays this information in real time to robotic arms. B, The robotic arms are attached to the operating room table and precisely control instrument tips that are positioned via ports within the surgical field. Two arms hold the surgical instruments, and a third arm is used to control the endoscope.

assisted endoscopic CABG. All patients underwent robotically assisted anastomosis of the left internal thoracic artery (LITA) to the left anterior descending coronary artery (LAD). Primary outcome measurements were device-related complications and graft patency at 6 to 8 weeks.

\section{Methods}

Patient selection. The Food and Drug Administration approved a 10-patient pilot study at 1 institution to examine the safety and efficacy of robotically assisted CABG with the Zeus Robotic Surgical System by Computer Motion (Goleta, Calif). It was stipulated that only the LITA-LAD anastomosis could be performed with the Zeus device. All other vessels were sewn by hand in the traditional fashion. Moreover, the procedure had to be performed with cardiopulmonary bypass (CPB) and cardioplegic arrest. After approval from our institutional review board, 15 patients were enrolled in the trial. Informed consent was obtained from each of the study participants. Patients were considered eligible if (1) they possessed angiographic evidence of occlusive ( $>50 \%$ stenosis) atherosclerotic disease of the LAD, (2) they required elective or urgent CABG surgery, and (3) they had had no previous cardiac operations. Exclusion criteria were as follows:

1. Patients over the age of 80 years

2. Patients with an ejection fraction of $40 \%$ or less

3. Patients having severe noncardiac conditions
4. Patients having severe peripheral vascular disease

5. Patients having myocardial infarction within 7 days before the procedure

6. Patients undergoing concomitant surgery, emergency surgery, or who have had previous thoracic surgery

7. Patients having calcified or diffuse disease in the LAD coronary artery

8. Patients participating in other investigational device or drug studies

Five enrolled patients were excluded from participation. The reasons for exclusion from the study were ejection fraction less than $40 \%$ (1 patient), the presence of a diffusely diseased or intramyocardial LAD (2 patients), myocardial infarction within 7 days of the operation (1 patient), and intraoperative hemodynamic instability before CPB (1 patient).

Operating room setup and monitoring. The patients were placed supine on the operating room table, and arterial and venous access was obtained. After induction of general anesthesia, the 3 robotic arms of the Zeus system were attached to the operating table (Fig 1, $B$ ). The patient and the robotic arms were then prepared and draped in a sterile fashion.

LITA harvest and CPB. For the first 9 patients, a standard median sternotomy was performed and the LITA was taken down in a traditional manner. The pericardium was opened and the heart was exposed. The patient was heparinized and the activated clotting time was maintained above 450 sec- 


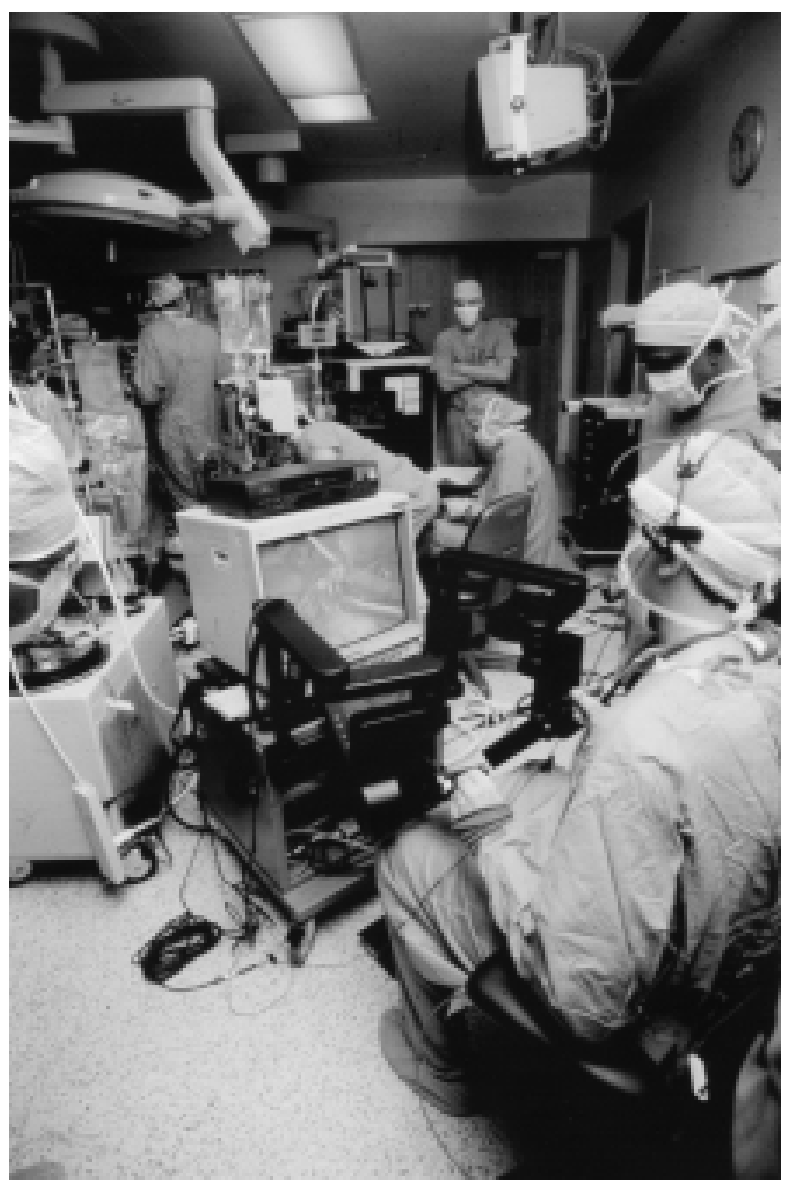

Fig 2. An intraoperative photograph of the surgeon performing robotically assisted endoscopic cardiac surgery. The surgeon is seated at the console approximately 5 yards from the patient. The operating room table can be seen in the background.

onds. The ascending aorta and right atrial appendage were cannulated and CPB was established. The patient was cooled to $32^{\circ} \mathrm{C}$. A cannula was placed in the aortic root for antegrade administration of cardioplegic solution and a coronary sinus catheter was placed for retrograde cardioplegia administration.

In the tenth patient, the LITA was harvested thoracoscopically through 3 endoscopic ports. The camera port was placed in the 4th intercostal space at the anterior axillary line and the 2 instrument ports were in the 2nd and 6th intercostal spaces in the mid axillary line. A small $(4 \mathrm{~cm})$ anterior thoracotomy was made in the 3 rd intercostal space. This patient was placed on CPB with the Heartport system (Heartport, Inc, Redwood City, Calif). ${ }^{12}$

Setup of robotic system. The Zeus Robotic Microsurgical System consisted of 2 robotic arms that were used to manipulate modified endoscopic instruments (Karl Storz, Culver City, Calif). The arms were attached to the operating table. The surgeon controlled the instruments by manipulating spe-

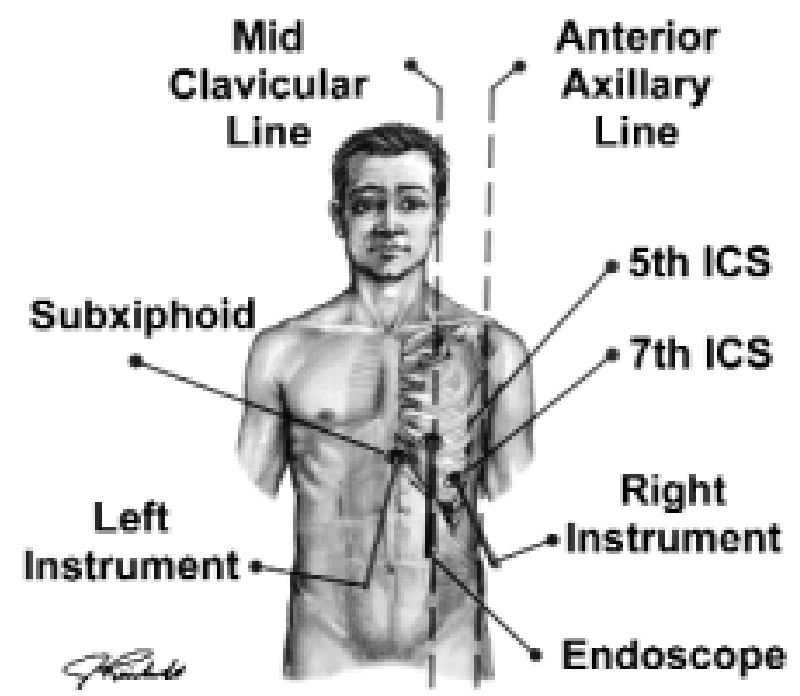

Fig 3. The positioning of the 3 ports used for the endoscopic anastomosis. A modified subxiphoid approach was used. The middle port was a $10-\mathrm{mm}$ port for the camera. Two instruments were placed through lateral and medial 5-mm ports. ICS, Intercostal space.

cially designed handles at a console (Fig 2). The handles allowed for 4 full ranges of motion (pan, roll, tilt, and in/out), as well as grasping. The surgeon's motions were directly and precisely translated from the console to the robotic arms by a computer controller. Custom-designed software allowed for tremor elimination, as well as motion scaling over a range of $2: 1$ to $10: 1$.

Three thoracoscopic ports were used to sew the anastomosis (Fig 3). This port placement was determined from our previous animal and cadaveric experience ${ }^{13}$ and was optimal for the LAD anastomosis in our hands. The 5-mm right instrument port (Endopath, Ethicon, Inc, Somerville, NJ) was in the midline just below the xiphoid process. The $10-\mathrm{mm}$ camera port (Endopath, Ethicon) was placed approximately $7 \mathrm{~cm}$ lateral to the midline port in the 5th or 6th intercostal space, depending on the position of the LAD. The 5-mm left instrument port was placed $7 \mathrm{~cm}$ lateral to the camera port in the 6 th or 7 th intercostal space along the anterior axillary line. A $0^{\circ}$ endoscope (Karl Storz) was used and attached to a 3-chip video camera (Tricam SL, Karl Storz) and light source (Zenon 300, Karl Storz). The endoscope was manipulated with the Aesop (Computer Motion) voice-controlled robotic arm. The video was monitored both at the surgeon console and on a 21-inch monitor at the head of the operating room table. The specialized instrument tips were inserted into the ports.

Administration of cardioplegic solution. In those patients who required grafts in addition to the LITA-LAD anastomosis, these grafts were performed first by means of traditional open chest methods. A crossclamp was applied to the ascending aorta, and cold blood cardioplegic solution was 


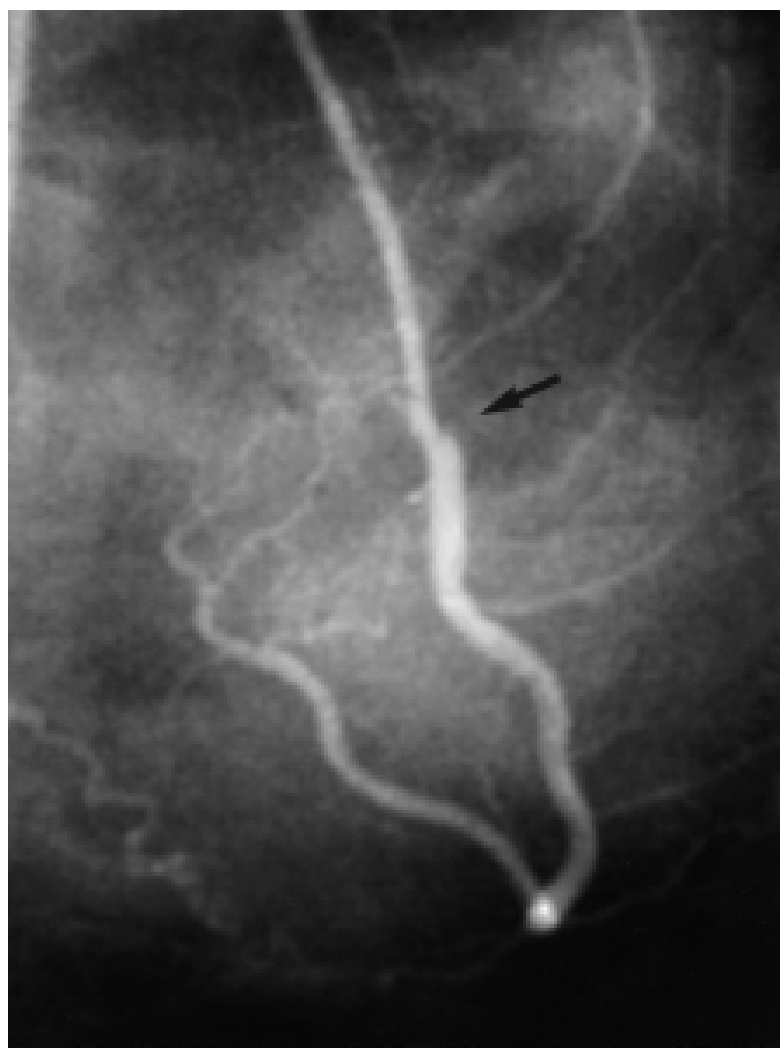

Fig 4. Angiogram at 8 weeks of a robotically sewn LITALAD graft. Anastomotic site is marked by the arrow. The angiogram demonstrates a patent anastomosis.

administered in an antegrade fashion to achieve arrest. Myocardial temperature was measured in the interventricular septum and maintained below $15^{\circ} \mathrm{C}$. Additional cardioplegic solution was given as necessary throughout the remainder of the operation in a retrograde fashion through the coronary sinus.

In the tenth patient, the Heartport Endoclamp device was used and cardioplegic solution was administered antegradely into the aortic root. Subsequently, cardioplegic solution was administered in a retrograde fashion through a percutaneously placed coronary sinus cannula.

Robotically assisted coronary anastomosis. The heart was left in situ and was not suspended in a pericardial cradle. The chest retractor was relaxed to allow a more normal anatomic position of the chest wall. After cardioplegic arrest, an arteriotomy was made in the distal LAD. In the last 5 patients, this was done with specialized scissors and the Zeus system. A continuous end-to-side anastomosis was performed endoscopically with the robotic instruments. The heel was sewn first and parachuted down, followed by completion of the toe of the anastomosis. No manipulation of the heart was necessary to perform the anastomosis, and visualization of each stitch through the subxiphoid camera port was excellent. An assistant held the LITA pedicle through the chest incision with standard instruments. The running anastomosis was performed with a specially designed 7-cm double-armed 7-0 polytetrafluoroethylene suture. ${ }^{*}$ Motion scaling (2.5:1) was used for each anastomosis. After completion of the anastomosis, the suture was tied endoscopically. No repair stitches were required. The clamp on the LITA and the aortic crossclamp were removed, and the patient was rewarmed. The patient was then weaned from CPB. Protamine sulfate was administered to reverse the heparin, and the chest was closed in a standard fashion. No patient required inotropic support.

Short-term graft flow. Blood flow through the LITA graft was measured with a 2.0 - to $2.5-\mathrm{mm}$ ultrasonic flow probe and flowmeter (HT311, Transonic Systems, Inc, Ithaca, NY) and was recorded with FlowTrace 32 software (Transonic Systems, Inc). If flow was not judged to be adequate, selective coronary angiography was performed in the operating suite. The LITA graft was selectively catheterized via the left radial artery. An OEC model 9600 digital imaging system was used to visualize the anastomosis (Omega Electronics Corporation, Salt Lake City, Utah).

Patient follow-up. During the postoperative period, the following data were collected: hemodynamic parameters, chest tube drainage, need for inotropic medications, length of intensive care unit stay, and length of hospital stay. Eight weeks after the operation, all patients underwent a second coronary angiogram of the LITA-LAD anastomosis to assess graft patency. Follow-up was $100 \%$.

\section{Results}

Patient demographics. Ten $(n=10)$ patients took part in the study, 6 men and 4 women. The mean age was $55.8 \pm 3.0$ years. Ejection fraction averaged $50 \% \pm$ $4 \%$.

Intraoperative results. The robotic system was quick and easy to assemble. The average time required for setup was $14.9 \pm 2.1$ minutes. No intraoperative complications related to port placement were encountered, and there were no mechanical failures of the robotic system.

The total number of grafts performed was $2.3 \pm 0.3$ per patient with a mean crossclamp time of $51.1 \pm 1.6$ minutes. The time required to perform the endoscopic LITA-LAD anastomosis with the robotic system was $23.6 \pm 1.4$ minutes (range 18-30 minutes). All anastomoses were successfully performed and no repair stitches were required.

The patient who had a limited thoracotomy and CPB with a Heartport device had a crossclamp time of 71 minutes and an anastomosis time of 28 minutes.

All patients underwent intraoperative ultrasonic determination of flow through the LITA graft. Eighty percent (8/10) of grafts measured were patent and had excellent diastolic flow. Average graft flow was $31 \pm 7$

${ }^{*}$ Gore-Tex suture; registered trademark of W. L. Gore \& Associates, Inc, Flagstaff, Ariz. 
$\mathrm{mL} / \mathrm{min}$. Two of the 10 grafts had inadequate flow and were taken down and reconstructed manually. In 1 case, the patient who had a Heartport procedure, an intraoperative coronary angiogram was performed. The graft was not visualized. However, the distal anastomosis was probe patent. A tentative diagnosis of graft spasm was made. In the second case, angiography was unavailable. Subsequent review of the videotape revealed a technical error. This case represented a failure of surgical technique, not of the robotic system. Conversion to the manual technique was easily accomplished in both patients, and all patients left the operating room with a patent LITA-LAD anastomosis.

Postoperative course. There was only one postoperative complication. This patient required return to the operating room the evening of surgery for excessive mediastinal hemorrhage. The source of hemorrhage was identified as the lateral trocar insertion site. The bleeding was stopped successfully with electrocautery.

No other complications were encountered in the postoperative period. The average length of stay in the intensive care unit was $1.1 \pm 1$ days. The average length of stay in the hospital was $4.1 \pm 0.2$ days.

Late follow-up. A $100 \%$ late follow-up was achieved. The mean period of follow-up was $142.1 \pm$ 10.7 days. No late complications occurred. All patients are presently in New York Heart Association class I.

Eight weeks after the operation, graft patency was assessed by a second coronary angiogram. These studies were all performed at our institution and revealed that $100 \%$ (8/8) of the LITA-LAD grafts were patent (Fig 4). One graft had a $50 \%$ stenosis at its insertion site.

\section{Discussion}

Minimally invasive surgical techniques have become more prevalent in the field of cardiac surgery. The potential benefits of these approaches include decreased blood loss, lower complication rates, and shorter hospital stays. ${ }^{14,15}$ Early results of beating heart procedures have demonstrated acceptable graft patency and minimal morbidity in large series of patients. ${ }^{2,16}$ However, with conventional techniques, completely endoscopic CABG has not been possible.

Recently, robotically assisted microsurgery systems have been introduced to increase the precision of endoscopic surgery. These computer-guided systems can control both surgical instruments ${ }^{8,9}$ and endoscopic cameras. ${ }^{17}$ These systems may help to overcome the obstacles to endoscopic CABG. Specifically, robotic instrumentation may provide access to multiple target vessels and offer the surgeon the ability to operate precisely in confined spaces. The most significant limitation to the use of traditional endoscopic instruments in
CABG is the lack of precision that results from the additive effects of instrument length and operator tremor. Robotic microsurgical systems address this limitation by filtering high-frequency motions, thus eliminating tremor. Dexterity is further enhanced through computer motion-scaling. This allows the surgeon to make large, easy-to-perform macroscopic movements at the console and have these scaled down by the computer to microscopic movements of the instrument tip inside the patient. Endoscopic magnification of the operative site also improves the accuracy of suture placement by providing enhanced visualization. The magnification is 3 to 4 times higher than that with traditional surgical loupes.

Finally, the Zeus system incorporates a robotic voicecontrolled arm (Aesop) to control the endoscope. This eliminates the need for an assistant and has been shown to improve the stability of the image, reduce camera clearings, and decrease the operative time during surgical procedures. ${ }^{17,18}$ It has been our early experience that this technology greatly facilitates microsurgery. Under high magnification, a stable image is absolutely critical. Moreover, the ability to control the movement of the Aesop robotic arm by voice effectively gives the surgeon a third arm.

In previous animal studies, endoscopic $\mathrm{CABG}$ has been shown to be feasible with acceptable short-term and long-term graft patency. ${ }^{11,13}$ The present study analyzed the short-term outcome of robotically assisted endoscopic CABG in human subjects. Short-term graft patency was $80 \%(8 / 10)$. Conversion to manual anastomosis was easily completed in the 2 patients with inadequate flow, and all patients left the operating room with patent LITA-LAD grafts. Graft patency 2 months after the operation was $100 \%(8 / 8)$ as demonstrated by angiography. These results demonstrate the feasibility of endoscopic CABG. More important, no device-related complications were observed. Anastomoses can be performed with robotic assistance with acceptable short-term results. The operating room time required for equipment setup was minimal.

The principal shortcoming of this study was that it does not represent a completely endoscopic approach. Other CABGs were performed through traditional incisions. Clearly, a completely endoscopic procedure will be a greater challenge, but one that appears to be achievable.

The other parts of endoscopic CABG have been performed without a surgical incision. Heartport technology allows for CPB without the need for a thoracic incision. ${ }^{19}$ Endoscopic LITA harvest is a widely described procedure $^{20,21}$ and can be easily performed manually. The use of an expensive robotic system does not seem to be warranted for this part of the procedure. 
Therefore we did not perform the LITA harvest with the robotic system. We did perform a manual endoscopic harvest of the LITA in 1 patient.

On the other hand, prior attempts to perform manual endoscopic coronary anastomoses have been fraught with difficulty and have not been clinically feasible. Robotic assistance does represent an enabling technology for this critical part of the procedure. This report indicates that the most difficult part of the procedure, the coronary anastomosis, can be performed endoscopically with robotic assistance. Early experience in Europe by Mohr's group ${ }^{22}$ at the University of Leipzig and Reichenspurner's group ${ }^{23}$ in Munich with endoscopic CABG also has been positive.

These early results with robotic systems suggest that a completely endoscopic approach to CABG is feasible in carefully selected patients. It is our belief that patient morbidity will be significantly reduced with this approach. However, further data are needed to support this hypothesis. It should be possible in human beings to perform multiple CABGs with an endoscopic approach and peripheral cannulation. Moreover, preliminary work in animal models and in the clinical setting suggest that beating heart approaches are also feasible. ${ }^{24}$

Our initial clinical experience indicates that robotic assistance is an enabling technology that allows for the performance of endoscopic CABG. Only time will tell whether the extra costs of this system will be justified by its potential advantages. Further clinical trials are warranted to explore the potential of this exciting new technology.

\section{REFERENCES}

1. Benetti FJ, Naselli G, Wood M, Geffner L. Direct myocardial revascularization without extracorporeal circulation: experience in 700 patients. Chest 1991;100:312-6.

2. Buffolo E, de Andrade JCS, Branco JNR, Teles CA, Aguiar LF, Gomes WJ. Coronary artery bypass grafting without cardiopulmonary bypass. Ann Thorac Surg 1996;61:63-6.

3. Calafiore AM, DiGiammarco G, Teodori G, Bosco G, D'Annunzio E, Barsotti A, et al. Left anterior descending coronary artery grafting via left anterior small thoracotomy without cardiopulmonary bypass. Ann Thorac Surg 1996;61:1658-65.

4. Izzat MB, Yim AP. Video-assisted internal mammary artery mobilization for minimally invasive direct coronary artery bypass. Eur J Cardiothorac Surg 1997;12:811-2.

5. Jansen EWL, Mansvelt Beck HJ, Grundeman PF, Bredee JJ. Facilitated exposure of the internal mammary artery in minimally invasive direct-vision CABG. Ann Thorac Surg 1997;63:1797-9.

6. Pagni S, Qaqish NK, Senior DG, Spence PA. Anastomotic complications in minimally invasive coronary bypass grafting. Ann Thorac Surg 1997;63:S64-7.

7. Mack MJ, Acuff TE, Casimir-Ahn H, Lonn UJ, Jansen EWL. Video-assisted coronary bypass grafting on the beating heart. Ann Thorac Surg 1997;63:S100-3.
8. Garcia-Ruiz A, Smedira NG, Loop FD, Hahn JF, Miller JH, Steiner CP, et al. Robotic surgical instruments for dexterity enhancement in thoracoscopic coronary artery bypass graft. J Laparoendosc Adv Surg Tech 1997;7:277-83.

9. Shennib H, Bastawisy A, Mack MJ, Moll FH. Computer-assisted telemanipulation: an enabling technology for endoscopic coronary artery bypass. Ann Thorac Surg 1998;66:1060-3.

10. Stephenson ER, Ducko CT, Sankholkar S, Hoenicke EM, Prophet GA, Damiano RJ Jr. Computer-assisted endoscopic coronary artery bypass grafting: a chronic animal study. Ann Thorac Surg 1999; 68:838-43

11. Stephenson ER Jr, Sankholkar S, Ducko CT, Damiano RJ Jr. Successful endoscopic coronary artery bypass grafting: an acute large animal trial. J Thorac Cardiovasc Surg 1998;116:1071-3.

12. Fann JI, Pompil MF, Burdeon TA, Stevens JH, Reitz BH. Port access coronary artery bypass grafting In: Cohen RG, Mack MJ, Fonger JD, Landreneau RJ, editors. Minimally invasive cardiac surgery. St Louis: Quality Medical Publishing; 1999. p.181-7.

13. Ducko CT, Stephenson ER Jr, Sankholkar S, Damiano RJ Jr. Robotically-assisted coronary artery bypass surgery: moving toward a completely endoscopic procedure. Heart Surg Forum 1999;2:29-37.

14. Magovern JA, Mack MJ, Landreneau RJ, Acuff TE, Benckart $\mathrm{DH}$, Hunter TJ, et al. The minimally invasive approach reduces the morbidity of coronary artery bypass [abstract]. Circulation 1996;94(Suppl):I52.

15. Doty JR, Fonger JD, Nicholson CF, Sussman MS, Salomon NW. Cost analysis of current therapies for limited coronary artery revascularization. Circulation 1997;96(Suppl):II16-20.

16. Calafiore AM, DiGiammarco G, Teodori G, Mazzei V, Vitolla G. Recent advances in multivessel coronary grafting without cardiopulmonary bypass. Heart Surg Forum 1998;1:20-5.

17. Kavoussi LR, Moore RG, Adams JB, Partin AW. Comparison of robotic versus human laparoscopic camera control. J Urol 1995; 154:2134-6.

18. Geis WP, Kim HC, McAfee PC, Kang JG, Brennan EJ Jr. Synergistic benefits of combined technologies in complex, minimally invasive surgical procedures: clinical experience and educational processes. Surg Endosc 1996;10:1025-8.

19. Stevens JH, Burdon TA, Peters WS, Siegel LC, Pompili MF, Vierra MA, et al. Port-Access coronary artery bypass grafting: a proposed surgical method. J Thorac Cardiovasc Surg 1996;111:567-73.

20. Nataf P, Lima L, Regan M, Benarim S, Ramadan R, Pavie A, et al. Thoracoscopic internal mammary artery harvesting: technical considerations. Ann Thorac Surg 1997;63:S104-6.

21. Wolf RK, Flege JB, Ohtselca JO. Technique with ultrasonic scalpel. In: Cohen RG, Mack MJ, Fonger JD, Landreneau RJ, editors. Minimally invasive cardiac surgery. St Louis. Quality Medical Publishing; 1999. p. 117-27.

22. Mohr FW, Falk V, Diegeler A, Autschbach R. Computerenhanced coronary artery bypass surgery. $\mathbf{J}$ Thorac Cardiovasc Surg 1999;117:1212-4.

23. Reichenspurner H, Damiano RJ, Mack M, Boehm DM, Gulbins $\mathrm{H}$, Meisner B, et al. Experimental and first clinical use of the voice-controlled and computer-assisted surgical system ZEUS for endoscopic coronary artery bypass grafting. J Thorac Cardiovasc Surg 1999;1-16.

24. Damiano RJ Jr, Reichenspurner H, Ducko CT. Endoscopic robotically-assisted coronary artery bypass grafting: present state-ofthe-art and future directions. Adv Card Surg. In press. 